UCRL-ID-134548

\title{
ACRV Instrumentation Plan For NMD HTK Light Gas Gun Tests
}

\author{
Douglas Dobie
}

April 12, 1999

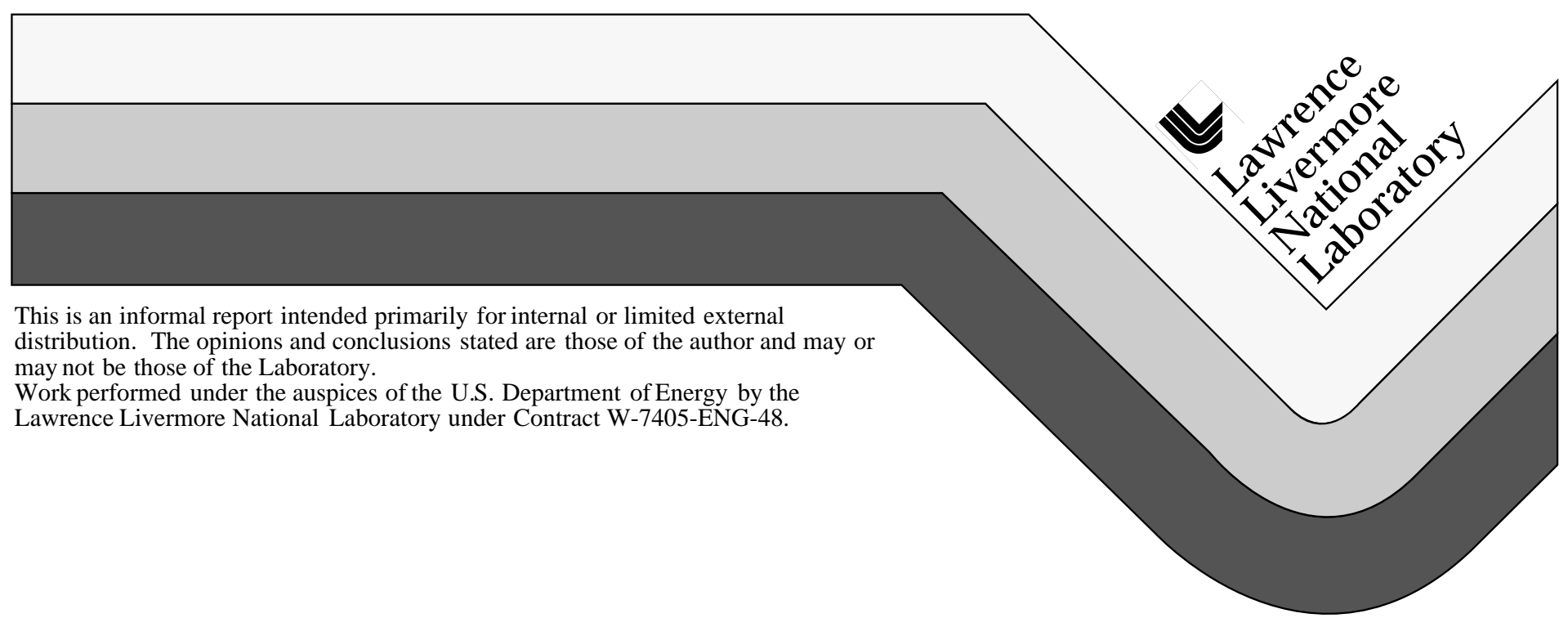




\section{DISCLAIMER}

This document was prepared as an account of work sponsored by an agency of the United States Government. Neither the United States Government nor the University of California nor any of their employees, makes any warranty, express or implied, or assumes any legal liability or responsibility for the accuracy, completeness, or usefulness of any information, apparatus, product, or process disclosed, or represents that its use would not infringe privately owned rights. Reference herein to any specific commercial product, process, or service by trade name, trademark, manufacturer, or otherwise, does not necessarily constitute or imply its endorsement, recommendation, or favoring by the United States Government or the University of California. The views and opinions of authors expressed herein do not necessarily state or reflect those of the United States Government or the University of California, and shall not be used for advertising or product endorsement purposes.

This report has been reproduced directly from the best available copy.

Available to DOE and DOE contractors from the Office of Scientific and Technical Information P.O. Box 62, Oak Ridge, TN 37831

Prices available from (423) 576-8401

Available to the public from the National Technical Information Service

U.S. Department of Commerce 5285 Port Royal Rd., Springfield, VA 22161 


\title{
ACRV Instrumentation Plan For NMD HTK Light Gas Gun Tests
}

\author{
April 12, 1999
}

Prepared by:

Douglas Dobie

Lawrence Livermore National Laboratory 


\section{Table of Contents}

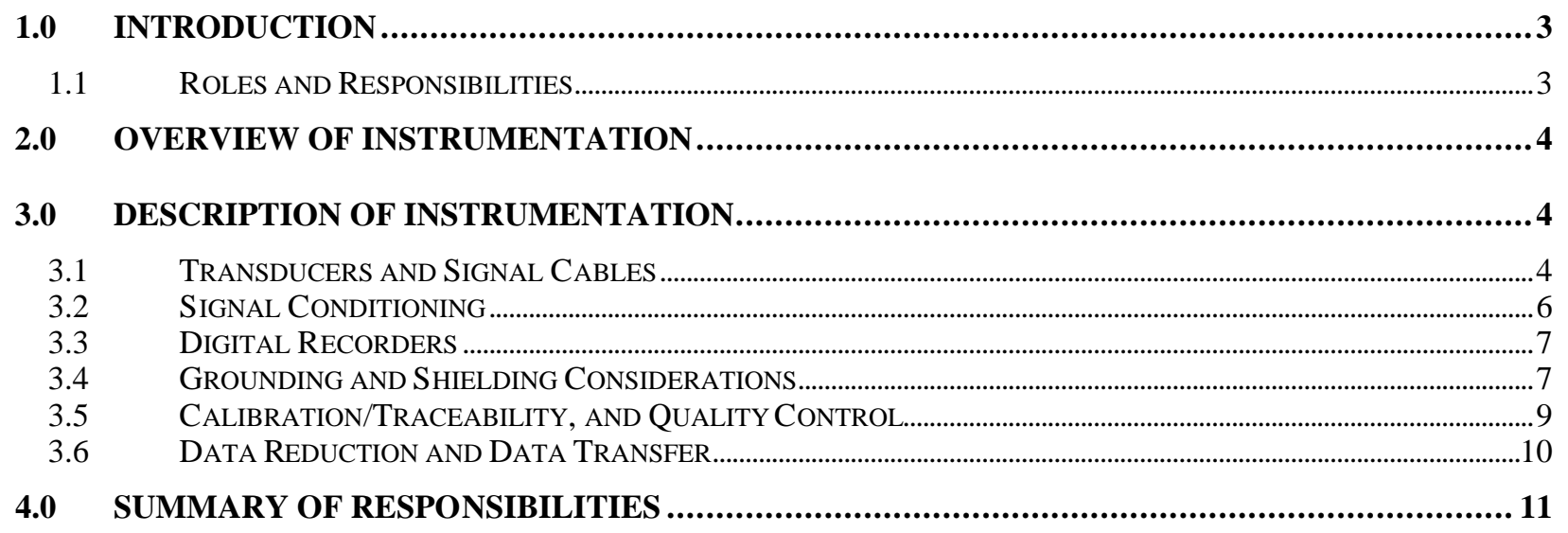




\subsection{Introduction}

In support of the NMD Hit-To-Kill Program for the US Army, twenty scaled tests on simulated nuclear targets are planned. The AEDC Light Gas Gun operated by Sverdrup Technology (SVT) in Tullahoma, TN will launch the scaled NMD projectile into scaled targets. The target for all the tests is a 1/4-scale version of the Attitude Controlled Re-Entry Vehicle (ACRV). The targets were designed and fabricated by Sandia National Laboratories (SNL) and Lawrence Livermore National Laboratory (LLNL). ITT Systems (ITT) is the integrating contractor for coordination of the multiple contractors involved in these tests. The targets are inert and contain no hazardous materials. The payloads have been instrumented to aid in post-test evaluation of the functional status of the postulated weapon systems. This document describes the instrumentation methods to be used on these tests.

\subsection{Roles and Responsibilities}

ITT is responsible for overall coordination and safety for these tests. ITT is responsible for hanging and alignment of the target in the test chamber and for determination of the projectile orientation and condition at the time of impact. ITT will mount an external foil gage on the point of expected impact with LLNL's guidance. ITT will also perform post-test debris recovery.

LLNL will provide target position requirements for each test and verify target alignment with ITT. LLNL is responsible for design and fabrication of the payload sub-assembly including associated instrumentation. LLNL will also perform post-test inspection of hardware, analysis of data, and reporting to characterize payload response. LLNL will provide instrumentation cables, Zippertube ${ }^{\mathrm{TM}}$, and \#8 ground wire from their sensors to reach outside the wall of the test section ( $\approx 30$ feet). LLNL will also provide SVT with charge integrators (from Dynasen, Inc), to be located outside at the data acquisition unit, for their sensors.

SNL is responsible for design and fabrication of the aeroshell. SNL will perform post-test inspection of hardware and reporting to characterize aeroshell response. SNL will install the payload per instructions from LLNL and ship the fully assembled target to AEDC. The assembled target will include instrumentation cables from their sensors to reach the wall of the test section $(\approx 30$ feet $)$.

SVT is responsible for operation of the gun and data acquisition. SVT and ITT will be responsible for interconnection and operation of the data acquisition system outside the test section as defined in this document, including signal conditioning provided by LLNL. SVT will supply an external foil gage on the point of expected impact. SVT will assume responsibility for the signals at the wall of the test section of the gun and will provide a patch panel port on the gas gun catch tank for all instrumentation. 


\subsection{Overview of Instrumentation}

Each of the targets will be instrumented with $\mathrm{PVF}_{2}$ (Poly-vinyl di-Floride) pressure gages and one TOAD (Time of Arrival Detector). The SVT data recorders will be triggered at a predetermined delay, after firing of the gun, to insure capture of the first and last signals from the target. After the test, data will be transferred as ASCII files to LLNL for further processing.

LLNL has installed $\mathrm{PVF}_{2}$ pressure sensors (17 channels) within the target payload sub-assembly to characterize payload response. LLNL will provide SVT with appropriate signal conditioners for these $\mathrm{PVF}_{2}$ sensors. LLNL will provide SVT with instructions for the calibration and use of the $\mathrm{PVF}_{2}$ sensors.

ITT will install one external TOAD at the expected point of impact on the RV after positioning the target in the test chamber. LLNL (or SVT) will provide a signal conditioner for this sensor. This TOAD will function as the reference timing point for all data reduction.

SVT and ITT will assemble a Data Acquisition System (DAS) including the signal conditioners for the $\mathrm{PVF}_{2}$ and TOAD sensor. SVT and ITT will perform appropriate instrumentation system checks, to verify proper operation, prior to connecting the target sensors to the system.

\subsection{Description of Instrumentation}

\subsection{Transducers and Signal Cables}

$\mathrm{PVF}_{2}$ gages are a commercial product of Dynasen Inc. for monitoring shock pressure. Figure 1 shows a typical $\mathrm{PVF}_{2}$ sensor. They are passive sensors that generate charge as a function of the rate of change in applied pressure. The output signal is applied to a passive RC integrator to produce a pressure record. These gages are utilized at various locations within the payload to produce shock pressure records. From these records, the amplitude of the shocks and timing within the payload can theoretically be determined.

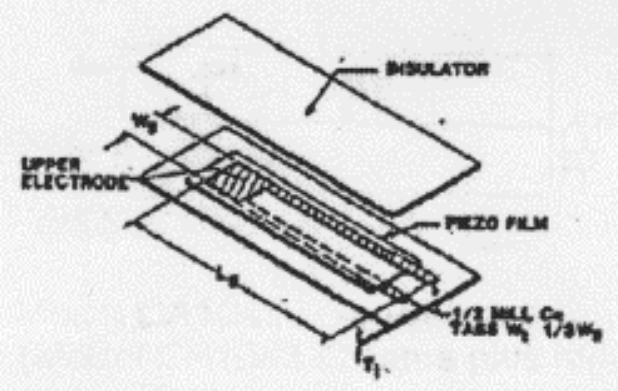

Typical Dynasen PVF2 Sensor Element 


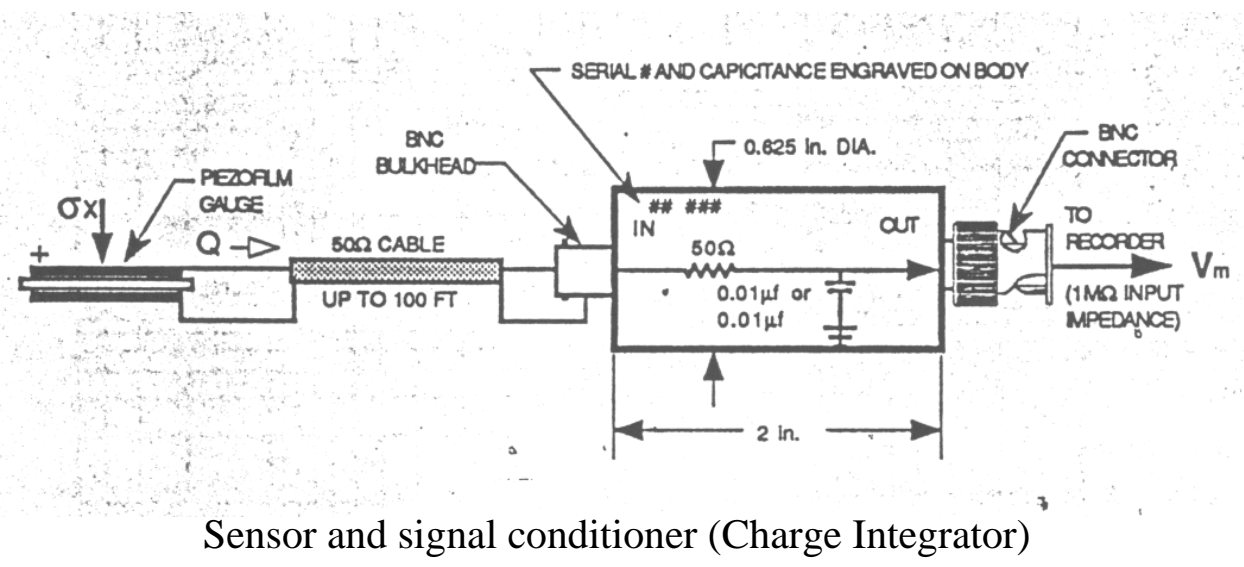

\section{Figure 1: Typical PVF2 Sensor and Charge Integrator}

A foil gage, constructed per Figure 2 (or equivalent), are to be used to indicate time of arrival of projectile at the expected impact point on the aeroshell.
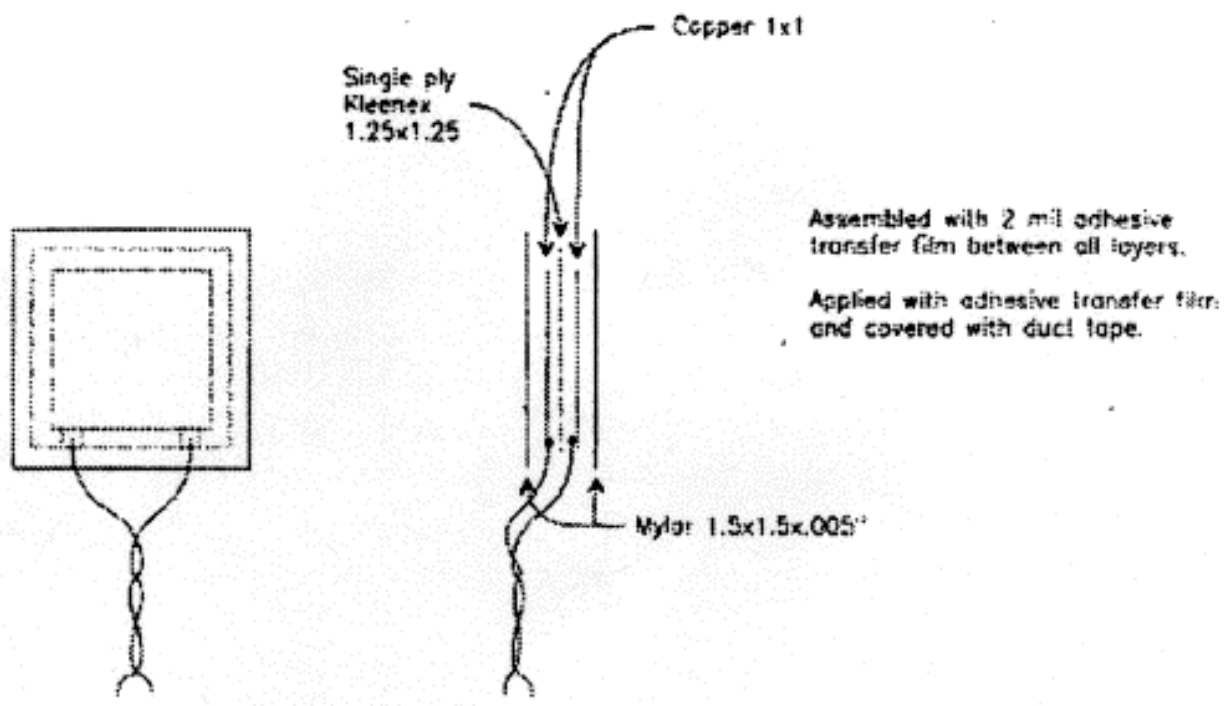

Figure 2: Construction of Foil Gage

Table 1 below summarizes the diagnostic instrumentation that will be used for these tests.

\begin{tabular}{c|l|l|l} 
Quantity & Sensor & Purpose & Supplier \\
\hline 1 & Foil TOAD & Time of First Contact & SVT \\
\hline 17 & PVF2 & Payload response (1 reference/noise) & LLNL \\
\hline
\end{tabular}

All signals are carried on RG174 cable from the target to a patch panel through the wall of the test section of the gun. LLNL will route the signal lines from within the targets in a manner to minimize unshielded exposure of the leads to debris generated during the tests. The goal of the instrumentation lead layout is to provide $1.5 \mathrm{~ms}$ of data, beyond first contact on the target, before the signal leads can be cut by test debris. 


\subsection{Signal Conditioning}

The PVF2 gages each require a charge integrator (Figure 1), supplied by LLNL, on the DAS input. The PVF2 integrators do not output excitation to the sensor, as the PVF2 sensors are selfgenerators of electrical charge.

LLNL or SVT will provide suitable signal conditioning for the foil switch TOAD mounted on the RV. This instrumentation consists of a RC discharge circuit that is triggered by closing of the foil switch. An LLNL signal conditioner is defined in Figure 5. LLNL will agree on method of signal conditioning for this TOAD if supplied by SVT. A 100ns, or less, time constant is recommended so that the make screen doesn't discharge into the RV.

\section{Figure 3: TOAD Signal Conditioner}
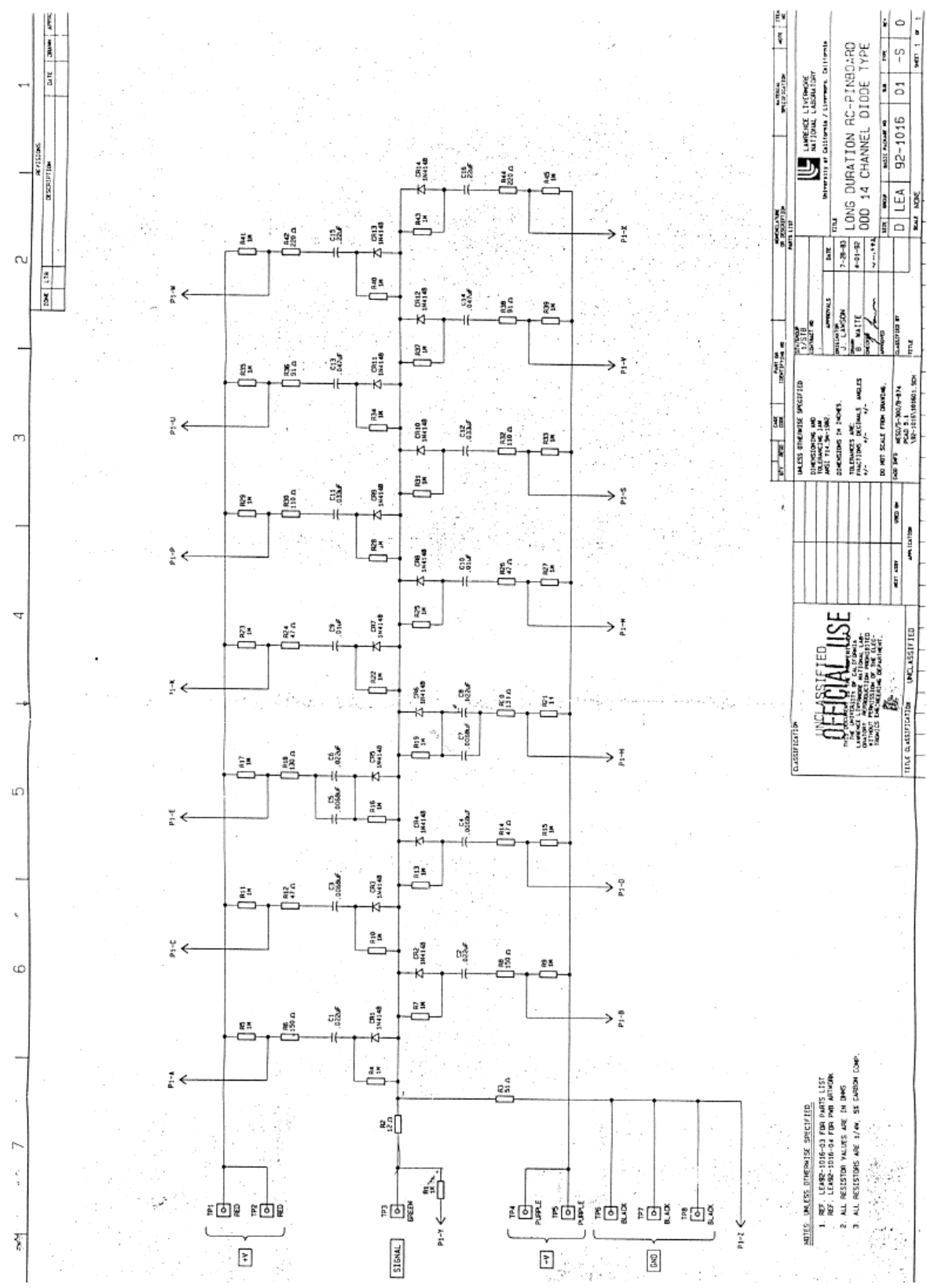


\subsection{Digital Recorders}

The PVF2 sensors will be recorded on $5 \mathrm{MHz} 12$ bit recorders (minimum). The TOAD sensor will be recorded on $5 \mathrm{MHz} 8$ bit recorders. Digital recorders will be synchronized with the time base of the flash x-ray data to allow correlation of digital data (PVF2 and make screen). In other words, an $x$-ray and make screen fiducial or timing mark is required with the PVF2 data.

A secondary trigger source is highly recommended for the data acquisition system in the event of a slow burn or other unforeseen anomalies. The flash x-ray or make screen is one source near the target that could supply this trigger.

\subsection{Grounding and Shielding Considerations}

We are attempting to make low signal measurements in an electrically noisy environment. Unfortunately, the physical arrangement of the PVF2 gages precludes the use of differential wiring and measurement. Therefore, we are attempting the next best thing; a driven ground system with target isolation, PVF2 cable shielding, DAS isolation, and careful attention to probable noise sources.

The metal substructure of the target will be electrically isolated from the gun and test chamber. The target will be suspended on non-conductive straps and signal leads will pass through the test chamber wall on isolated connectors. The DAS shall provide single ended inputs for the signals.

Both leads to the foil gage and PVF2 gages are electrically isolated from the aeroshell and are therefore isolated within the target. Several noise checkout runs will be performed prior to the test to determine the best test setup of signal ground to maximize signal to noise ratio. SVT, LLNL, and ITT will work together to minimizing noise and crosstalk in the data acquisition channels between the x-ray source, foil switch and PVF2 gages.

It is recommended that the system be setup as shown in Figure 6,7 and 8. Figure 6 applies specifically to the foil switch, Figure 7 to the PVF2 gages and Figure 8 to the complete instrumentation system. The signal reference point for the foil circuit should be common at the DAS. The PVF2, RG174 cables may be shielded with Zippertubing ${ }^{\mathrm{TM}}$ (supplied by LLNL) to the patch panel, and from the patch panel to the DAS. These two pieces of Zippertubing shall be electrically connected through an isolated conductor through the patch panel. The Zippertubing shall be electrically connected to the aeroshell. The PVF2 signal will be connected to single ended inputs at the DAS. The Zippertubing will remain electrically isolated from the PVF2 signal lines at the DAS and connected to the instrumentation rack which functions as a Faraday shield. The DAS racks need to be physically insulted or isolated from ground with plastic or wood (i.e., the driven ground plane). The driven ground consists of a wood-metal-wood sandwich. The metal (3/8" to 1/2" aluminum) is connected to the \#8 copper wire and is connected to a nearby building ground.

LLNL will provide a vacuum tight ground lug to allow connections through the patch panel. The Target will be connected to a single point ground inside the test chamber, to the patch panel lug, to the driven ground plane, and to a building ground near the DAS via a \#8 insulated copper wire (also provided by LLNL).

Noise mitigation for the PVF2 instrumentation also necessitates an isolation transformer for the DAS. The transformer should have a capacitance $\leq 1 \mathrm{pF}$ between the primary and secondary coils. Any connections to the DAS modules (i.e., GPIB, other devices to be measured) should be optically isolated so that these ground loops are avoided. 


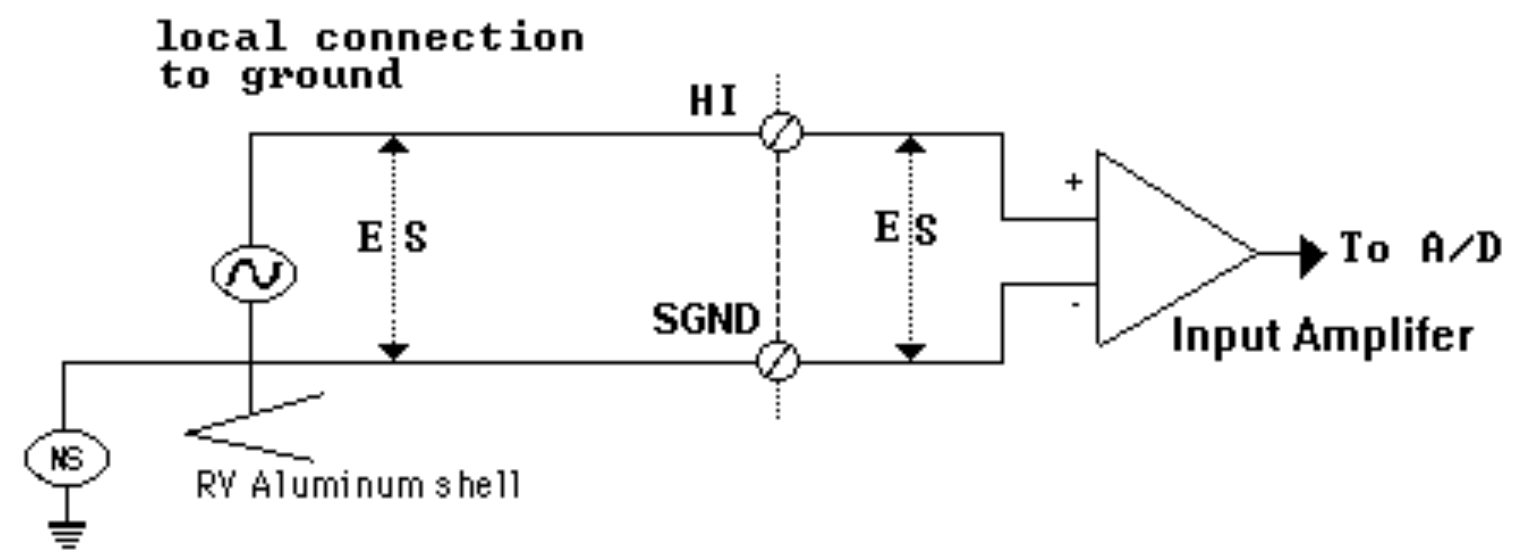

Figure 4: Single-Ended Configuration for foil switch

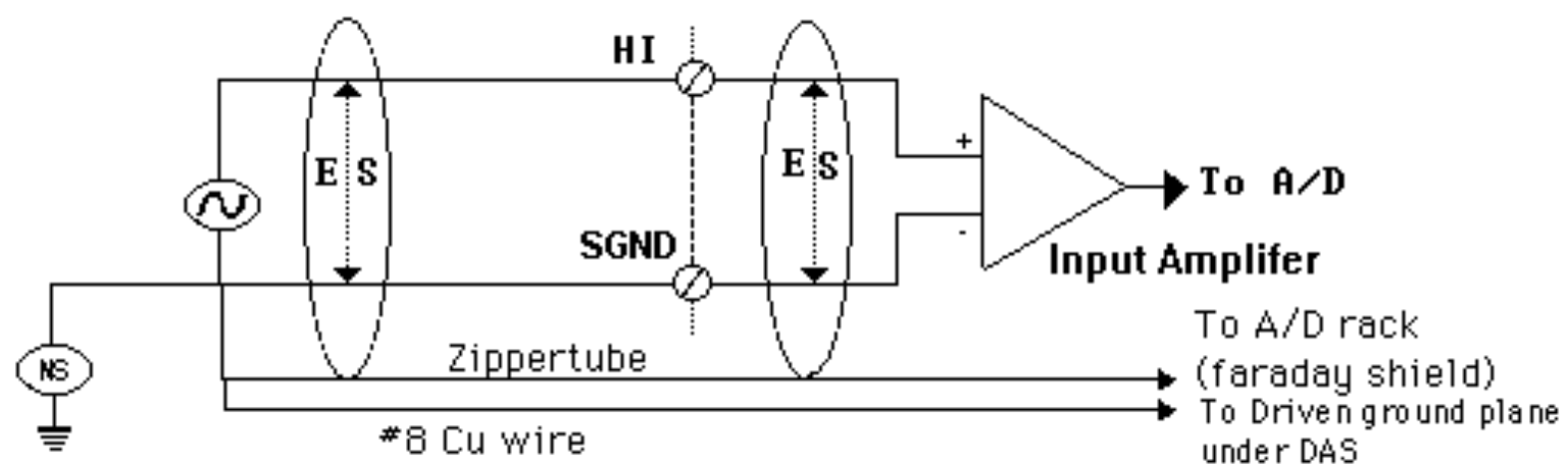

Figure 5: Single-Ended Configuration for the PVDF gages 


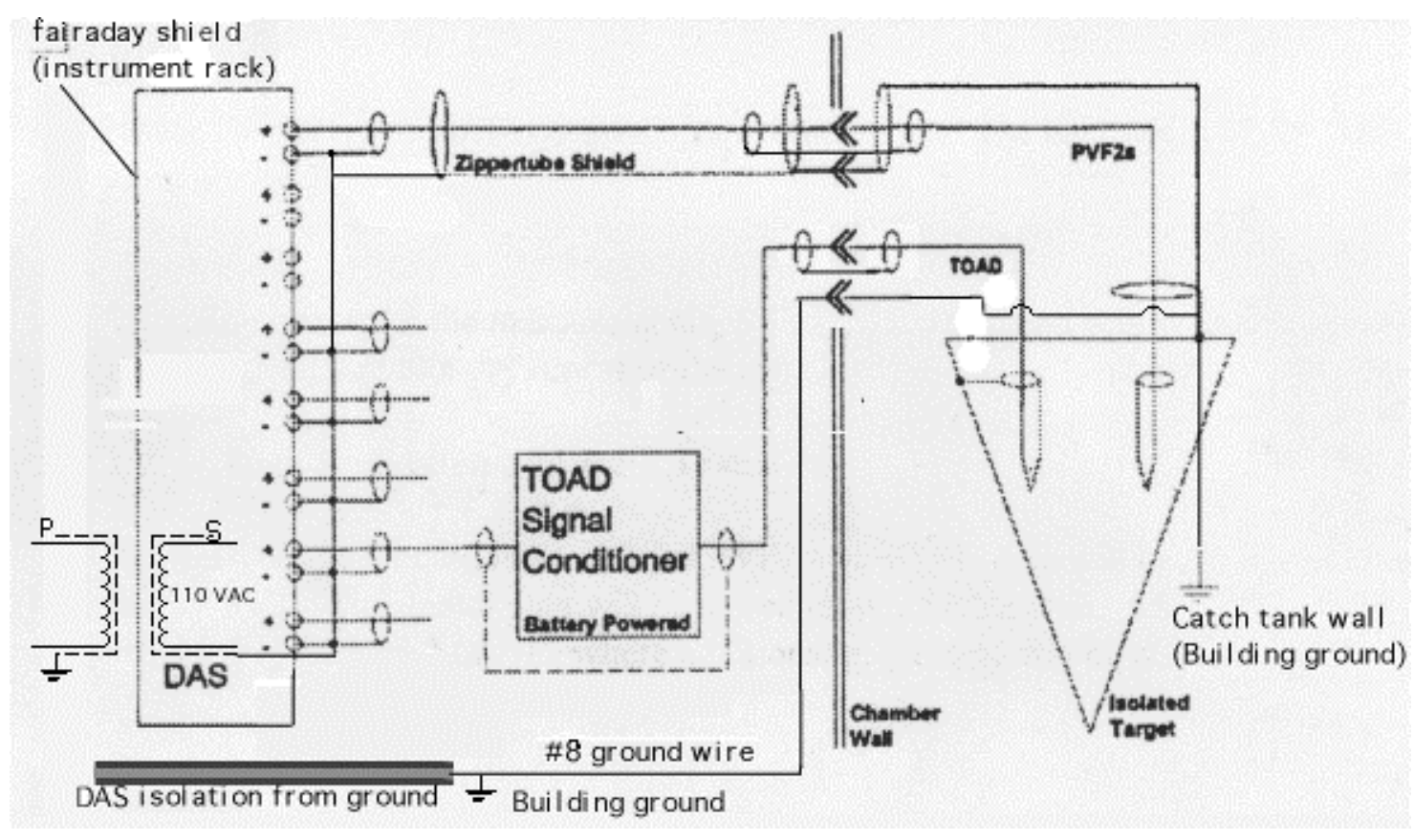

Figure 6: Grounding/Shielding Schematic

\subsection{Calibration/Traceability, and Quality Control}

All measurements will be made in a manner that assures NIST traceability. The digitizers must be within their annual calibration period. The annual calibration is to be done using NIST traceable instruments, shunt calibration methods, and end-to-end calibrations using voltage insertion from a calibrated source. SVT will perform an end-to-end calibration of the gain/attenuation of the PVF2 circuit (less the integrators). This end-to-end calibration will also serve to verify proper calibration of the digitizer timebase and amplitude sensitivity by comparisons with a calibrated source prior to the test.

SVT and LLNL will perform an end-to-end calibration to determine the bandwidth (BW) and transfer efficiency (TE) for each PVF2 channel. After removing the Dynasen integrator, connect a function generator to the input to the DAS and measure the voltage amplitude $\left(\mathrm{V}_{\mathrm{DAS}}\right)$, then compare this to the voltage amplitude when the function generator is connected near the sensor $\left(\mathrm{V}_{\text {Sensor }}\right)$. The transfer efficiency (TE) for each PVF2 channel is then:

$$
\mathrm{TE}=\mathrm{V}_{\text {Sensor }} / \mathrm{V}_{\mathrm{DAS}}
$$

Determine the system bandwidth for each of the PVF2 channels with the Dynasen charge integrator in place. Connect a function generator near the sensor of a PVF2 gage (i.e. at the barrel connector) and input a precision square wave:

$$
\mathrm{BW}=0.35 / \mathrm{t}_{\mathrm{r}}
$$

where $t_{r}$ is the 10 to $90 \%$ rise time of the square wave. The bandwidth of the DAS must be greater than $700 \mathrm{kHz}$.

To assure quality of the measurements, SVT will develop and follow an instrumentation checklist, and conduct dry run(s) of the test. 


\subsection{Data Reduction and Data Transfer}

Plots of voltage amplitude vs. time of PVF2 and TOAD data will be produced after each test by SVT. The digital data will be stored on removable disk. ASCII files will be provided to LLNL where additional processing will be done. 


\subsection{Summary of Responsibilities}

ITT: overall conduct of testing functions including safety coordinate activities with LLNL, SNL, and SVT to assure that test needs are met rigging of targets at desired engagement conditions install external foil gage at point of impact determination of actual engagement conditions

LLNL: design and assembly of payload sub-assembly install PVF2 gages in payload provide engagement conditions for each test post-test inspection, analysis, and reporting of payload response verify alignment of the target with ITT provide instrumentation requirements to SVT, e.g., band edge limits, gage factors data format/processing provide a vacuum tight ground lug provide \#8 ground wire and connectors provide signal conditioner for external foil gauge at point of impact provide Zippertubing ${ }^{\mathrm{TM}}$ for PVF2 RG174 cabling provide cables from PVF2 gages to test section wall provide charge integrators for installation by SVT provide an isolator, noise suppressor transformer for the DAS

SNL: design and assemble target aeroshell post-test inspection, analysis, and reporting of aeroshell response

SVT: provide Data Acquisition System (DAS) for recording data from test (PVF2, Foil TOAD) provide calibration of DAS for LLNL and ITT sensor conduct "dry runs" to verify all equipment functionality provide ASCII data files to LLNL for processing provide time history plots of all data channels provide external foil gage at point of impact (and possibly its signal conditioner) 